\title{
Developing Regional Sustainability Index as a New Approach for Evaluating Sustainability Performance in Indonesia
}

\author{
Andrea Emma Pravitasari ${ }^{1,2, *}$, Ernan Rustiadi ${ }^{1,2}$, Setyardi Pratika Mulya ${ }^{1,2}$, Lutfia Nursetya Fuadina ${ }^{2}$ \\ ${ }^{1}$ Center for Regional Systems, Analysis, Planning and Development (P4W/CRESTPENT), Bogor Agricultural University (IPB), \\ Jl. Raya Pajajaran, IPB Baranangsiang Campus, Bogor, West Java, Indonesia \\ ${ }^{2}$ Regional Development Planning Division, Department of Soil Science and Land Resource, Faculty of Agriculture, \\ Bogor Agricultural University, Jl. Meranti, IPB Darmaga Campus, Bogor, West Java, Indonesia
}

Copyright $\odot 2018$ by authors, all rights reserved. Authors agree that this article remains permanently open access under the terms of the Creative Commons Attribution License 4.0 International License

\begin{abstract}
Sustainable development has been the subject of considerable discussion and it has attracted much attention among environmentalist, economist and policy makers. There are few studies of sustainable development measures in Indonesia, but still focused on partial dimension. This study tried to develop index to promote sustainable development assessment in Indonesia, especially at the regional (regency and municipality) level, called Regional Sustainability Index (RSI) using Factor Analysis (FA) with consideration of regional-scale spatial interdependency by employing Local Indicator of Spatial Association (LISA) statistics. There are 416 regencies and 98 municipalities in Indonesia. The data used in this study were secondary data obtained from the Central Statistics Agency (BPS) in 2014. RSI was developed based on 30 regional sustainable development indicators which were divided into 3 major dimensions: economy, social, and environment. Some indicators which develop RSI is covering economic welfare, public services, infrastructure, social welfare, community health and education, physical condition, regional environmental sustainability and disaster resilience. Based on LISA results, it was found that sustainability performance of the regional-scale spatial units (regencies/municipalities) was strongly influenced by the sustainability conditions in its surrounding areas. The approach developed in this study was able to show the actual condition of regional sustainability performance in all dimensions without making it into one composite index so that it could show the index value of each dimension. According to the results, we can conclude that RSI is a very effective method to indicate the locations of the hotspot issues of sustainable development. By this index, we have a new approach for evaluating and reporting economic, social, and environmental conditions at the regional level to support the integration of three dimensions of sustainability. The study concludes that the country has
\end{abstract}

attained high socio-economic sustainability which needs to be addressed. Producing a cluster map of regencies and municipalities by combining the RSI value of each dimension is very helpful for the decision maker to determine the appropriate policy for solving the problems in each region.

Keywords Cluster Analysis, Factor Analysis, LISA Statistics, Sustainable Development, Environmental and Socio-Economic Sustainability

\section{Introduction}

Sustainable development has been the subject of considerable discussion and it has attracted much attention among environmentalist, economist, and policy makers. The term Sustainable Development (SD) is widely used in the current political and environmental discourses. The vagueness of the term allows it to be appropriated by different social groups with different positions regarding development. Part of the imprecision is inherent in the concept itself, which depending on the approach and by whom is the approach may take different connotations [1]. Sustainability can be thought as living within the constraints of environmental, technological and social needs, while sustainable development is the process of moving to the point where all human activity is sustainable. The Brundlant Commission in 1987 described sustainable development as development that seeks to meet the needs of the present generation without compromising the ability to meet those of the future [2].

To achieve and maintain sustainability, policy-makers require timely information which demonstrates whether a system is generally becoming more or less sustainable, and 
specific information on which characteristics need the most improvement [3]. Whereas the acceptance of sustainable development itself as a policy goal has stimulated interest in measuring the degree of result based on the use of indicators according to the same level of consideration on economic, social and environmental impacts [4]. Therefore, to ensure an optimized and effective step towards sustainability, the progress and shortcomings need to be monitored and measured. Based on that reason, the assessment of sustainable development needs to be figured as the measurement of sustainability. In order to achieve this goal, it is necessary to set a limited number of easy understandable indicators [5]. Indicators are only a tool which can simply be to make a problem visible, and many other factors can influence a policy process and increasingly recognized for policy making and public communication in conveying information on countries' performance in fields such as environment, economy, society, or technological development $[6,7]$.

Based on OECD definition [8], an indicator is a variable which describes one characteristic of the state of a system, usually through observed or estimated data. Some indicators may give information about the position of the system relative to particular sustainability boundaries or goals ("distance-to-target" indicators). When many indicators are used, they are either presented in a framework of categories, or aggregated into an index. An "index" is a quantitative aggregation of many indicators and can provide a simplified, coherent, multidimensional view of a system. It is agreed that indicators should represent the main structures, processes, and functions of the economic, ecological, and social fields of the city-region referring to the problems and targets determined in the normative dimension (problem and target-oriented representativeness) [9].

Currently, Indonesia is undergoing a historic transformation from a rural to an urban economy. Based on World Bank Report [10], the country's cities are growing faster than in other Asian countries at a rate of $4.1 \%$ per year. In 2016, not more than $47 \%$ of the people living in rural areas, the rest are live in urban areas. With the exception of a few provinces, the rural populations of Indonesia are relatively poorer than the urban ones therefore Indonesia has experienced a process of rapid and continued increased urbanization. Based on that rapid urbanization, Indonesia has the third-largest amount of urban land in East Asia, after China and Japan. Rapid urbanization such an achievement of economic transition. The good economic transition performance in the other hand, sometimes cost at environmental deterioration. Therefore, to achieve the goal of sustainability, while developing economic sector should not only focused in gain the economic profit but also give attention to the social transition and environmental preservation as well [11].
Some previous researches tried to review and compared the indices developed to measure sustainable development [12-17]. A comprehensive review and comparative assessments of six types of sustainability indices was conducted by Wilson et al.[18] and concluded there is 'lack of a clear direction at the global level in how best to approach sustainable development'. Strezov et al.[19] analysed nine different indices for their ability to measure the economic, environmental and social dimensions of sustainable development. Those nine indices are Change in Wealth Index (CWI), Ecological Footprint (EF), Environmental Performance Index (EPI), Environmental Sustainability Index (ESI), Genuine Savings Index (GSI), Global Well-Being Index (GWI), Happy Planet Index (HPI), Human Development Index (HDI) and Sustainable Society Index (SSI). Based on Strezov et al.[19], only two indices (SSI and GSI) considered all three dimensions of sustainable development, while the remaining measured either the socioeconomic, socio-environmental or just economic and environmental dimensions.

In line with some previous researches, there are few studies of sustainable development measures in Indonesia, but still focused on partial dimension. Therefore, the objectives of this study were: (1) to develop Regional Sustainability Index (RSI) using Factor Analysis (FA) with regency/ municipality as the unit of analysis; (2) to capture the spatial distribution of RSI for identifying the sustainability condition in every region (regency/municipality) in Indonesia; and (3) to analyze spatial association of RSI between locations by employing Local Indicator of Spatial Association (LISA) statistics. Identifying the relationship or spatial association of RSI is also important, since at the local level there is spatial interdependecy between locations. So, the sustainability performance in a location is affected by the sustainability condition in its surrounding areas [20]. The final objective of this study is to produce the clustering map of regencies and municipalities in Indonesia by combining the index value of economy, social, and environmental dimension using cluster analysis.

\section{Study Area}

This study area is located in Indonesia which consists of 34 provinces, 416 regencies and 98 municipalities. Geographically, Indonesia is located between $6^{\circ}$ north latitude to $11^{\circ}$ South latitude and $95^{\circ}$ to $141^{\circ}$ East longitude. Strategic geographical location in South East Asia, lying between the Indian Ocean and the Pacific Ocean. The total area of Indonesia is $1,919,317 \mathrm{~km}^{2}$. With the capital of Jakarta, Indonesia has more than 17.000 islands of which 5 are big islands namely: Sumatera Island, Kalimantan Island, Java Island, Sulawesi Island, and Papua Island (Figure 1). 


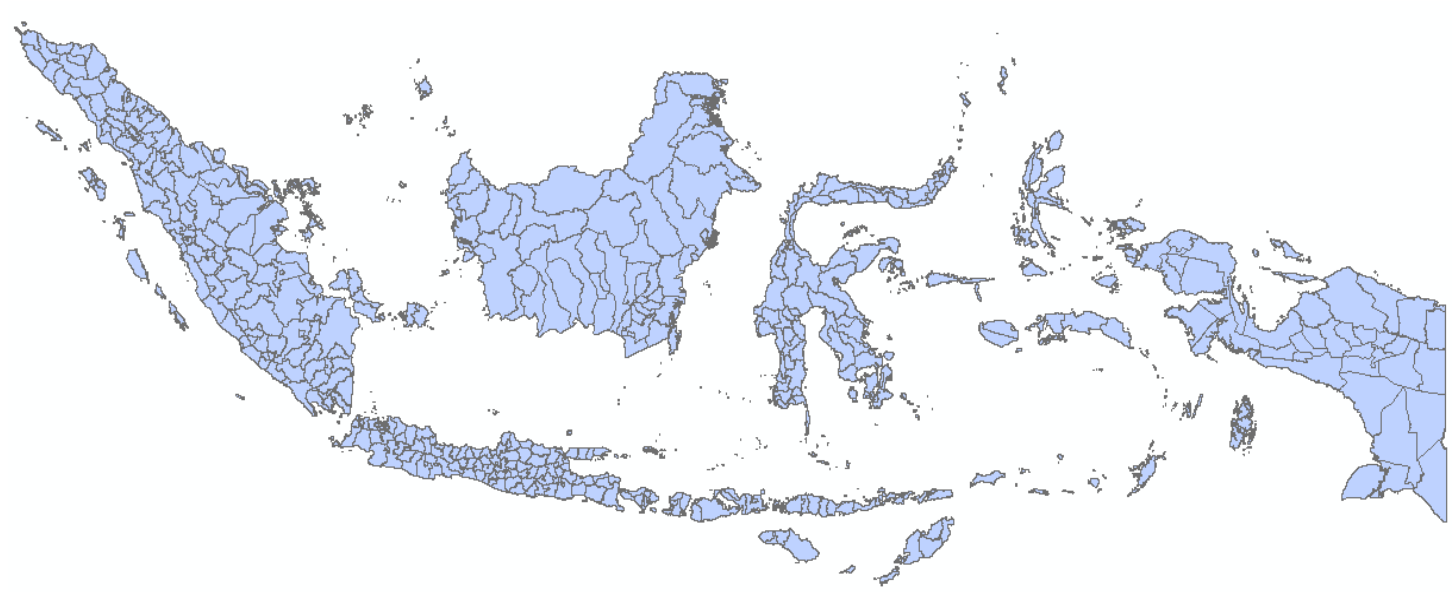

Figure 1. The administration map of Indonesia

\section{Material and Methods}

In this research, we used Regional Sustainability Index (RSI) as the index to measure sustainable development in the regions of Indonesia. RSI was developed based on 30 variables (indicators) which were divided into 3 aspects: economy, social, and environment (Table 1). RSI was developed by employing Factor Analysis (FA) to select the variables/indicators. Factor analysis (FA) is a statistical method used to describe variability among observed, correlated variables in terms of a potentially lower number of unobserved variables called factors.

The FA model used in this study can be written as follows:

$$
R S I_{k i}=\sum_{m=1}^{n k} E_{k m} . S_{k m i}
$$

Where: $R S I k i=\mathrm{RSI}$ for $k$-th dimension on $i$-th region; $k=$ Dimension ( $k=1$ : economy; $k=2$ : social; $k=3$ : environment); $E k m=$ Eigenvalue for $k$-th dimension on $m$-th factor; $S_{k m i}=$ Factor score for $k$-th dimension, $m$-th factor on $i$-th region; $i=1,2,3, \ldots, \mathrm{n}$. To standardize RSI value $\left(R S I_{k i}(s t d)\right)$ in scale $0-100$, we used this formulation:
$R S I_{k i}(s t d)=\left(R S I_{k i}-R S I_{k i}(\min )\right) * \frac{100}{R S I_{k i}(\max )-R S I_{k i}(\min )}(2)$

A weights or contiguity matrix is used to impose a neighborhood structure of the data to assess the extent of similarity between locations and values. There are two basic categories of neighbor definitions: contiguity-based weights (shared borders and/or vertices) and distance-based weights. The formula of Global and Local Moran's I or LISA statistic can be seen as follows:

$$
\begin{gathered}
I=\frac{\sum_{i=1}^{n} \sum_{j}^{n} W_{i j}\left(R S I_{k i}-\overline{R S I_{k}}\right)\left(R S I_{k j}-\overline{R S I_{k}}\right)}{Z_{R S I_{k}}^{2} \sum_{i=1}^{n} \sum_{j=1}^{n} W_{i j}} \\
I_{\mathrm{i}}=\frac{\sum_{j=1}^{n} W_{i j}\left(R S I_{k i}-\overline{R S I_{k}}\right)\left(R S I_{k j}-\overline{R S I_{k}}\right)}{Z_{R S I_{k}}^{2} \sum_{j=1}^{n} W_{i j}}
\end{gathered}
$$

Where: I= Global Moran's Index; $\mathrm{I}_{\mathrm{i}}=$ Local Moran's I or LISA statistics; $R S I_{k i}=$ the value of RSI for $\mathrm{k}$-th dimension on $\mathrm{i}$-th regency/municipality; $R S I_{\mathrm{k}}=$ the average value of $\overline{R S I_{k}} ; \mathrm{W}_{\mathrm{ij}}=$ contiquity matrix; representing the proximity of i-th region i's and region j's locations; $\mathrm{n}=$ the total number of regency/municipality; $Z^{2} R S I_{k}=$ the variance of the $R S I_{k}$. 
Table 1. List of Variables Forming RSI

\begin{tabular}{|c|c|}
\hline Code & Variables \\
\hline \multicolumn{2}{|c|}{ ECONOMY $(\mathrm{k}=1)$} \\
\hline V1 & Percentage of households that work in the agricultural sector $(\%)$ \\
\hline $\mathrm{V} 2$ & Percentage of households that used electricity $(\%)$ \\
\hline V3 & Number of industry per 1,000 population \\
\hline V4 & Number of market, minimarket, shop per 1,000 population \\
\hline V5 & Number of hotels, hostels, motels, and inns per 1,000 population \\
\hline V6 & Distance to the bank $(\mathrm{km})$ \\
\hline V7 & Distance to the market $(\mathrm{km})$ \\
\hline V8 & Distance to the central business district (CBD) $(\mathrm{km})$ \\
\hline V9 & Local infrastructure index (scalogram index) \\
\hline V10 & Percentage of secondary and tertiary sector to the total GDP $(\%)$ \\
\hline \multicolumn{2}{|c|}{ SOCIAL $(\mathrm{k}=2)$} \\
\hline V11 & Number of the formal education facilities (kindergarten to university) per 1,000 population \\
\hline V12 & Number of health facilities (hospitals, clinics, health centers, doctors, pharmacies) per 1,000 population \\
\hline V13 & Number of people suffering from malnutrition per 1,000 population \\
\hline V14 & Number of mortality per 1,000 population \\
\hline V15 & Number of toddler death per 1,000 population \\
\hline V16 & Number of maternal mortality per 1,000 population \\
\hline V17 & Number of incidents on fight of citizen \\
\hline V18 & Average distance to the entertainment venue/facilities (pub, cinema) $(\mathrm{km})$ \\
\hline V19 & Average distance to the health facilities (hospitals, clinics, health centers, pharmacies) $(\mathrm{km})$ \\
\hline V20 & Average distance to the formal education facilities (kindergarten to university) $(\mathrm{km})$ \\
\hline \multicolumn{2}{|c|}{ ENVIRONMENT (k=3) } \\
\hline V21 & Number of drought events \\
\hline V22 & Number of floods events \\
\hline V23 & Number of landslide events \\
\hline V24 & Percentage of household living along the river (riparian area) (\%) \\
\hline V25 & Percentage of household living in the slum area $(\%)$ \\
\hline V26 & Number of people suffering from malaria per 1,000 population \\
\hline V27 & Number of people suffering from respiratory tract infection per 1,000 population \\
\hline V28 & Number of people suffering from diarrhea and vomit per 1,000 population \\
\hline V29 & Percentage of village occurring water pollution (\%) \\
\hline V30 & Land conversion from agricultural land (excluding rice field) to non-agricultural land (ha) \\
\hline
\end{tabular}

Then, we conducted cluster analysis in order to perform grouping of objects, so objects in one group have characteristics that are more similar than objects in other groups. According to Saefulhakim [21], the level of similarity between objects can be illustrated through the value of diversity and/or distance. The smaller the value of diversity between objects that one with another object then the characteristics will be more similar. The closer the distance between one object with another object then the characteristics will also be more similar. Cluster analysis, firstly proposed by Tryon in 1939, which describes the algorithms and methods for grouping objects that have similarities based on consideration of certain categories must thus determine the number of classes as well as the memberships of the observations to the groups based upon two or more variables [22, 23].

For clustering analysis, since the degree of similarity becomes important, it is necessary to standardize the data for each of the different main characteristics/categories/ main characteristics. This is important because it affects the distance and/or diversity values between individual areas. The standardization can be done using equation:

$$
z_{i, j}=\frac{x_{i, j}-\bar{x}_{. j}}{\operatorname{stdev} x_{. j}}
$$

Where: $z_{i j}=$ Standardized data for the $\mathrm{i}$-th region and the main characteristics/ categories/j-th main characteristic; $x_{i j}$ $=$ The origin data for the $\mathrm{i}$-th region and the main 
characteristics/ categories/identifiers for $\mathrm{j}$-th; $\bar{x}_{. j}=$ The average value of the i-th region for each characteristic/ category/main character of $\mathrm{j}$-th; stdev $x_{j}=$ The standard deviation value (i standard deviation) of the $i$-th region for each characteristic/category/main characteristic of $j$.

Then we determined the rules or definitions that will be used to determine the distance between regions based on the characteristics or categories used. In this study, the degree of similarity between individuals was measured using the Euclidean Distance method. Euclidean distance is a calculation of the distance between individuals based on the geometric distance or the distance of a straight line in a multidimensional space. The equation for calculating euclidean distance is developed from the Phytagoras equation. Equations for calculating euclidean distance as follows:

$$
d_{i, i}=\sqrt{\sum_{j}\left(X_{i, j}-X_{i^{i}, j}\right)^{2}}
$$

Where: $d_{i, i}=$ the distance between the $\mathrm{i}$-th individual to the $\mathrm{i}$-th individual which measured in some of the characteristics/categories/the principal characteristic of $\mathrm{j}$-th; $X_{i, j}=$ the size of the $\mathrm{i}$-th individual in the character/category/main characteristic of $\mathrm{j}$-th; $i=$ individu; $j=$ characteristic/category/main characteristic $\mathrm{j}$-th.

In cluster analysis, clustering can be done through 2 mechanisms namely hierarchycal clustering method and non-hierarchycal clustering method. Hierarchycal Clustering Method is a grouping method that is done based on the distance between individuals by using certain grouping rules. This grouping rule aims to measure the degree of similarity or incompatibility between groups. Each grouping will form a hierarchical structure based on the distance between individuals called dendograms. According to Saefulhakim [21], in principle the rules of formation of this group can be classified as in Figure 2. It can be seen that the 2 dimensions of non-cluster mismatch in principle can be based on 2 approaches namely distance approach and variation approach.

In this study the intermediate group/cluster dexterity uses the Ward method. This method is in principle different from the others, because it uses a variety approach to evaluate the distance between clusters. The Ward method tries to find the pair of objects or clusters where the merging of the two will result in the sum of the least squares distance between objects with the centroid of the cluster. The sum of squares of distance is what can also be termed "error" in Analysis of Variety (Anova).

In contrast to the hyrarchical clustering method that submits the grouping process based on linkage rules or amalgamation rules, the non-hyrarchical clustering method of the number of groups have been established from the beginning. After we determined the number of groups of $\mathrm{k}$, the initial centroid point $\mathrm{k}$ will be determined by a particular method. Furthermore each data point will be clustered based on euclidean distance to the centroid point that had been determined. The general equations of distance determination as follows:

$$
D_{(i, k)}=\sqrt{\frac{1}{M} \cdot \sum_{j=1}^{M}\left(X_{i, j}-\bar{X}_{j}^{(k)}\right)^{2}}
$$

Where: $D_{(i, k)}=$ the distance between the i-th data point and the k-centroid; $M=$ The number of variables Xj; $\overline{X_{j}^{(k)}}$ $=$ The mean values of variables $\mathrm{j}$ and cluster $\mathrm{k}$.

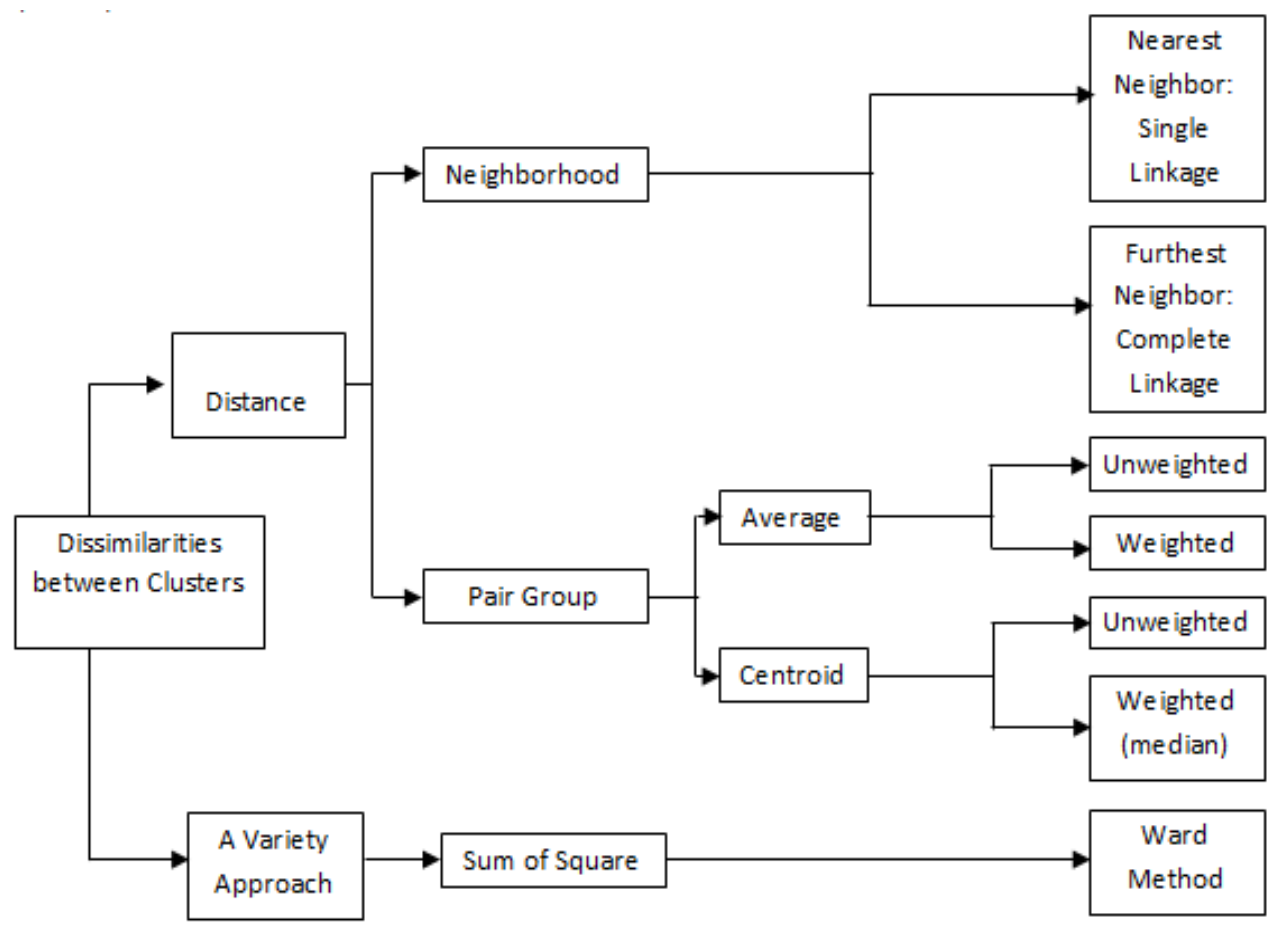

Figure 2. Inter-Cluster dissimilarities size (Source: Saefulhakim, 2008). 


\section{Result and Discussion}

In this study, we developed index to promote assessment of sustainable development in Indonesia, especially at the regional (regency and municipality) level by using FA to select key performance indicators/variables to forming RSI for each aspects: economy $\left(\mathrm{RSI}_{1}\right)$, social $\left(\mathrm{RSI}_{2}\right)$, and environment $\left(\mathrm{RSI}_{3}\right)$. FA selected 3 factors from 10 variables which represent RSI for economic dimension $\left(\mathrm{RSI}_{1}\right)$ that shown in Table 2. Based on factor loading's values, factor 1 is represented by percentage of households that used electricity (\%) (V2), distance to the bank (km) (V6), distance to the market (km) (V7) and distance to the central business district (CBD) (km) (V8). Those mentioned indicators are showing the accessibility to some economic facilities. Then, factor 2 is represented by percentage of households that work in the agricultural sector (\%) (V1) and percentage of secondary and tertiary sector to the total GDP (\%) (V10). Factor 3 is represented by number of market, minimarket, shop per 1,000 population (V4).

Table 2. Factor loading of economic factor analysis

\begin{tabular}{|c|c|c|c|}
\hline Var & Factor 1 & Factor 2 & Factor 3 \\
\hline v1 & 0,389936 & $\mathbf{- 0 , 7 5 9 0 2 8}$ & $-0,115902$ \\
\hline v2 & $\mathbf{0 , 7 0 1 2 1 6}$ & 0,022244 & 0,331534 \\
\hline v3 & 0,166171 & $-0,404365$ & 0,375257 \\
\hline v4 & 0,170669 & $-0,182783$ & $\mathbf{0 , 7 1 6 3 5 5}$ \\
\hline v5 & $-0,163648$ & 0,110654 & 0,615500 \\
\hline v6 & $\mathbf{- 0 , 7 6 4 6 2 6}$ & 0,087981 & 0,046054 \\
\hline v7 & $\mathbf{- 0 , 9 0 0 8 7 1}$ & 0,079851 & $-0,028262$ \\
\hline v8 & $\mathbf{- 0 , 9 2 3 1 1 3}$ & $-0,007980$ & $-0,085674$ \\
\hline v9 & 0,377701 & 0,477076 & 0,638362 \\
\hline v10 & 0,499067 & $\mathbf{0 , 7 0 4 9 5 1}$ & $-0,018758$ \\
\hline Expl.Var & 3,367364 & 1,524521 & 1,574289 \\
\hline Prp.Totl & 0,336736 & 0,152452 & 0,157429 \\
\hline Eigenvalue & 3,535789687 & 1,6415962 & 1,28878788 \\
\hline \% Total & 35,35789687 & 16,415962 & 12,8878788 \\
\hline Cumulative & 35,35789687 & 51,773859 & 64,6617377 \\
\hline
\end{tabular}

For social aspects, FA also determined 3 factors from 10 variables which representing RSI that shown in Table 3. Factor 1 is represented by average distance to the entertainment venue/facilities (pub, cinema) (km) (V18), average distance to the health facilities (hospitals, clinics, health centers, pharmacies) (km) (V19) and average distance to the formal education facilities (kindergarten to university) $(\mathrm{km})(\mathrm{V} 20)$. Factor 2 is represented by number of the formal education facilities (kindergarten to university) per 1,000 population (V11) and number of health facilities (hospitals, clinics, health centers, doctors, pharmacies) per 1,000 population (V12). Factor 3 is represented by number of mortality per 1,000 population (V14), number of toddler death per 1,000 population (V15), and number of maternal mortality per 1,000 population (V16).
Table 3. Factor loading of social factor analysis

\begin{tabular}{|c|c|c|c|}
\hline Var & Factor 1 & Factor 2 & Factor 3 \\
\hline v11 & 0,408174 & $\mathbf{0 , 7 4 5 0 6 5}$ & 0,177853 \\
\hline v12 & $-0,032114$ & $\mathbf{0 , 8 4 9 4 5 8}$ & 0,151233 \\
\hline v13 & 0,182138 & 0,076700 & 0,236985 \\
\hline v14 & $-0,129224$ & 0,161129 & $\mathbf{0 , 8 7 8 9 9 4}$ \\
\hline v15 & 0,580049 & $-0,120194$ & $\mathbf{0 , 7 3 4 9 3 6}$ \\
\hline v16 & 0,325337 & $-0,093912$ & $\mathbf{0 , 7 8 6 1 0 0}$ \\
\hline v17 & 0,157938 & $-0,549896$ & 0,346549 \\
\hline v18 & $\mathbf{0 , 8 1 9 8 3 0}$ & 0,221602 & 0,015503 \\
\hline v19 & $\mathbf{0 , 9 3 8 1 5 1}$ & 0,004116 & 0,191879 \\
\hline v20 & $\mathbf{0 , 8 2 2 2 3 4}$ & $-0,169408$ & 0,292677 \\
\hline Expl.Var & 2,913071 & 1,712020 & 2,284193 \\
\hline Prp.Totl & 0,291307 & 0,171202 & 0,228419 \\
\hline Eigenvalue & 3,814138 & 1,716743 & 1,378403 \\
\hline \% Total & 38,14138 & 17,16743 & 13,78403 \\
\hline Cumulative & 38,14138 & 55,30881 & 69,09284 \\
\hline
\end{tabular}

For environmental aspects, FA determined 3 factors from 10 variables which representing RSI that shown in Table 4. Factor 1 is represented by number of people suffering from malaria per 1,000 population (V26), number of people suffering from respiratory tract infection per 1,000 population (V27), number of people suffering from diarrhea and vomit per 1,000 population (V28). Factor 2 is represented by number of drought events (V21) and land conversion from agricultural land (excluding rice field) to non-agricultural land (ha) (V30). Factor 3 is represented percentage of household living along the river (riparian area) (\%) (V24) and percentage of desa occurring water pollution (\%) (V29).

Table 4. Factor loading of environmental factor analysis

\begin{tabular}{|c|c|c|c|}
\hline Var & Factor 1 & Factor 2 & Factor 3 \\
\hline v21 & 0,182385 & $\mathbf{0 , 7 3 6 0 2 5}$ & 0,107171 \\
\hline v22 & $-0,028415$ & 0,662865 & $-0,096283$ \\
\hline v23 & $-0,146521$ & 0,587098 & 0,370118 \\
\hline v24 & 0,144247 & 0,101060 & $\mathbf{- 0 , 7 4 2 7 8 3}$ \\
\hline v25 & $-0,175507$ & $-0,153028$ & $-0,466925$ \\
\hline v26 & $\mathbf{0 , 8 1 6 5 2 3}$ & $-0,012759$ & 0,077793 \\
\hline v27 & $\mathbf{0 , 8 2 7 4 4 1}$ & 0,025150 & 0,013608 \\
\hline v28 & $\mathbf{0 , 9 1 0 1 8 5}$ & $-0,010118$ & 0,009610 \\
\hline v29 & $-0,083865$ & 0,120477 & $\mathbf{- 0 , 7 6 1 7 5 6}$ \\
\hline v30 & $-0,031971$ & $\mathbf{0 , 7 0 5 4 5 7}$ & $-0,221109$ \\
\hline Expl.Var & 2,295012 & 1,872519 & 1,562979 \\
\hline Prp.Totl & 0,229501 & 0,187252 & 0,156298 \\
\hline Eigenvalue & 2,310770 & 1,871373 & 1,548366 \\
\hline \% Total & 23,10770 & 18,71373 & 15,48366 \\
\hline Cumulative & 23,10770 & 41,82144 & 57,30510 \\
\hline
\end{tabular}

Figure 3 explained regarding the spatial distribution values of each $\mathrm{RSI}_{1}, \mathrm{RSI}_{2}$ and $\mathrm{RSI}_{3}$. $\mathrm{RSI}_{1}$ explained on (Figure 3(a)) shows that the higher value of the RSI mostly concentrated in Java island and northern part of Sumatera island. This condition means that regencies and municipalities in Java Island have better economic performance compare to regencies and municipalities in other islands. In the other hand, $\mathrm{RSI}_{2}$ (Figure 3(b)) shows 
the opposite condition. Most of that regencies and municipalities are dominated by moderate value, except regencies and municipalities that located in Java Island which have low value. While on the $\mathrm{RSI}_{3}$, (Figure 3(c)) regencies and municipalities are mostly dominated by moderate value. Whereas the higher value located in some regencies and municipalities in southern part of West Java Province, northern part of Papua island, and west part of Sumatera Island which refer to good environmental condition.
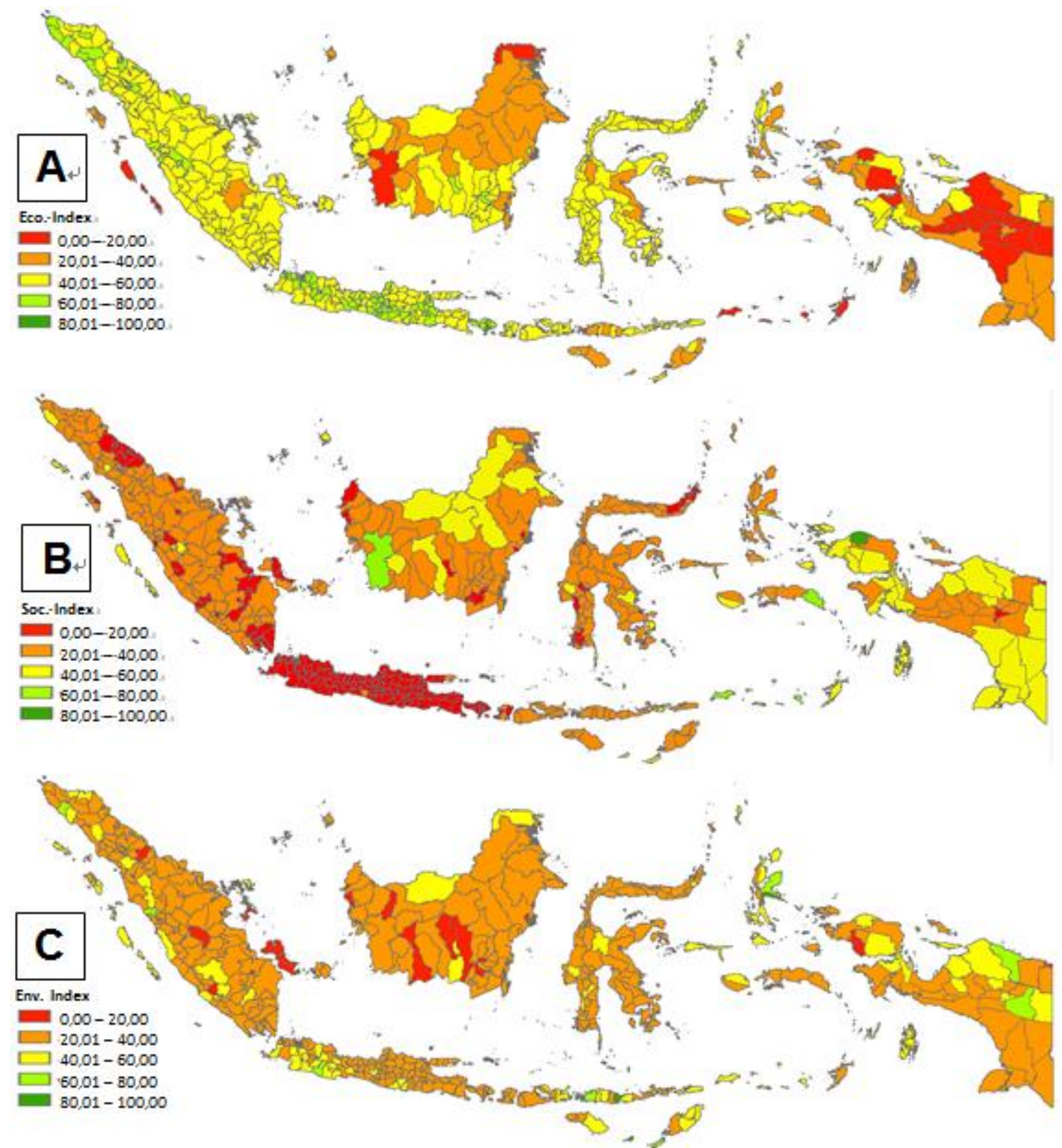

Figure 3. (a) Regional Economy Index $\left(\mathrm{RSI}_{1}\right)$; (b) Regional Social Index (RSI $)$; (c) Regional Environmental Index (RSI $)$

Then, spatial association of regional economic, social, and environmental index based on LISA statistics are presented in Figure 4. The spatial distribution of all dimensions of RSI value were showed with considering its influence of the neighboring regencies/municipalities. 

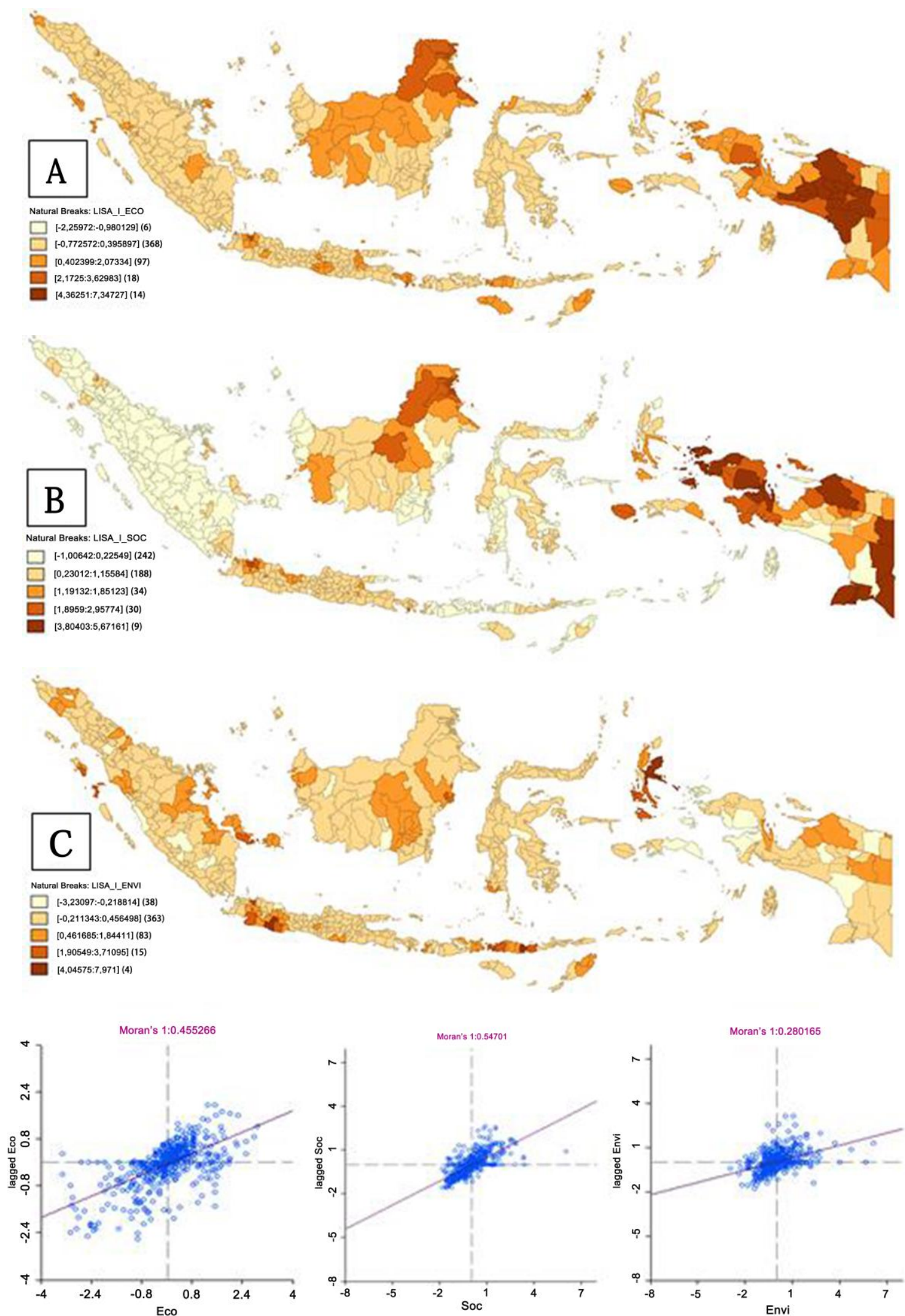

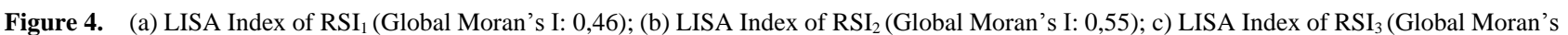
I: 0,28$)$

Based on the result, the regional social sustainability index $\left(\mathrm{RSI}_{2}\right)$ has the highest Global Moran's I (0.55) (Figure 4(b)), while the regional environmental sustainability index $\left(\mathrm{RSI}_{3}\right.$ ) has the lowest Global Moran's I (0.28) (Figure 4(c)). The regional economy sustainability index $\left(\mathrm{RSI}_{3}\right)$ has Global Moran's I 0.46 (Figure 4(a)). 

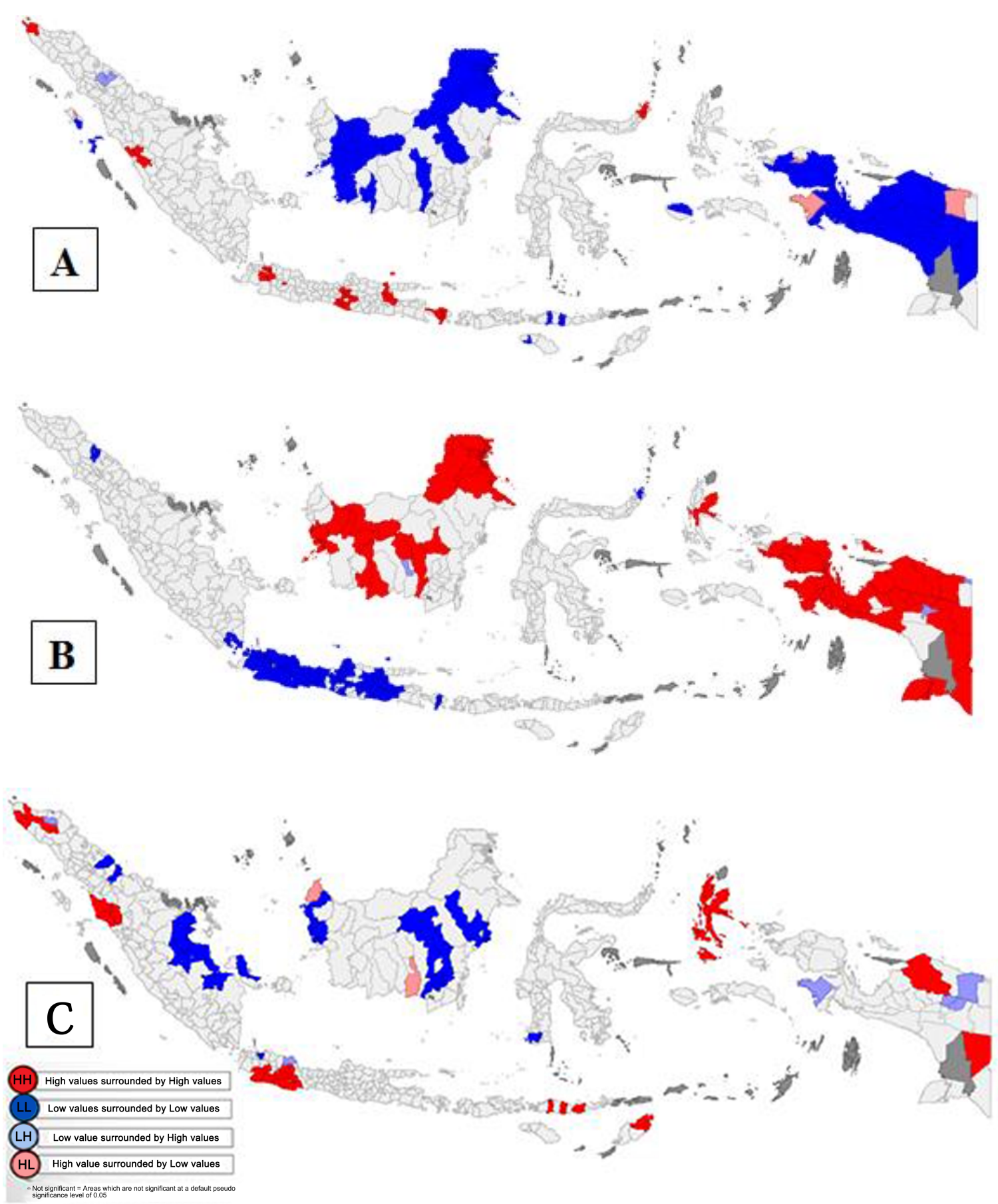

Figure 5. (a) Spatial Association of $\mathrm{RSI}_{1}$; (b) Spatial Association of $\mathrm{RSI}_{2}$; (c) Spatial Association of $\mathrm{RSI}_{3}$

Spatial association of RSI in each aspects are presented in Figure 5. The result showed that the H-H (high-high) spatial associations of the $\mathrm{RSI}_{1}$ are located in several numbers of regencies and municipalities in Java Island, Sumatera Island, Bali Island, and small numbers in northern part of Sulawesi Island. It means that those districts are having high regional economic index. On the other hand, the L-L (low-low) spatial associations of the $\mathrm{RSI}_{1}$ are located mostly in Papua Island and several numbers of regencies and municipalities in Kalimantan Island which reflected to low level of economic condition.
The opposite condition happened in $\mathrm{RSI}_{2}$, the L-L (low-low) spatial associations of the $\mathrm{RSI}_{2}$ is concentrated in Java Island, while the $\mathrm{H}-\mathrm{H}$ (high-high) spatial associations of the $\mathrm{RSI}_{2}$ are concentrated in several numbers of regencies and municipalities in Papua Island and Kalimantan Island. While in $\mathrm{RSI}_{3}$, the $\mathrm{H}-\mathrm{H}$ (high-high) spatial associations are spread off in Maluku Island, southern part of West Java Province, some regencies and municipalities in Sumatera Island, Papua Island and Nusa Tenggara Timur Province. The L-L (low-low) spatial associations of $\mathrm{RSI}_{3}$ are concentrated in several regencies 
and municipalities in South Sumatera Province and Kalimantan Island.

The final output of this study is to produce the cluster map of regencies and municipalities based on the regional sustainability index value $\left(\mathrm{RSI}_{1}, \mathrm{RSI}_{2}\right.$, and $\left.\mathrm{RSI}_{3}\right)$. Actually, there are 27 groups/typologies by combining the value of RSI in all three dimensions (Figure 6). However, according to the result, there are only 4 clusters produced by clustering analysis. The distribution member of each cluster can be seen in Figure 7.

The principal of clustering analysis is minimizing varians within group and maximizing varians between group. It means that there is a distinction between groups/clusters, however, each group/cluster shows the similarity within the members. Based on the cluster analysis results which presented in Figure 7, it can be seen that Cluster 2 has the most members consists of 229 regencies and municipalities (45\%), which was determined by moderate value in all aspects/dimensions. Members of Cluster 2 are scattered throughout Indonesia. The second largest cluster is cluster 3 that consists of 149 members $(30 \%)$.
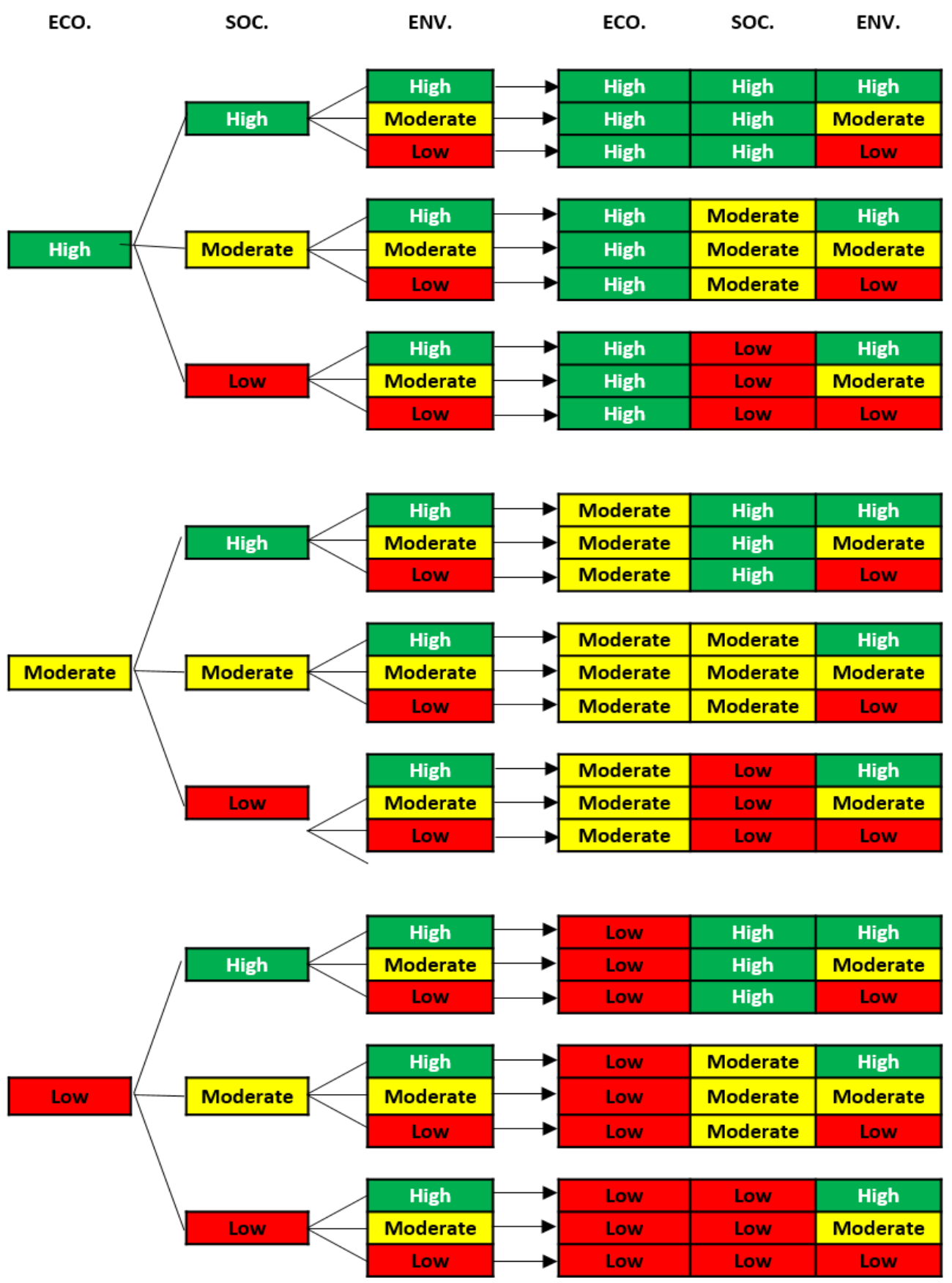

Figure 6. Combination of Typologies Based on $\mathrm{RSI}_{1}$ (Economy), $\mathrm{RSI}_{2}$ (Social), and $\mathrm{RSI}_{3}$ (Environmental) Index Value 


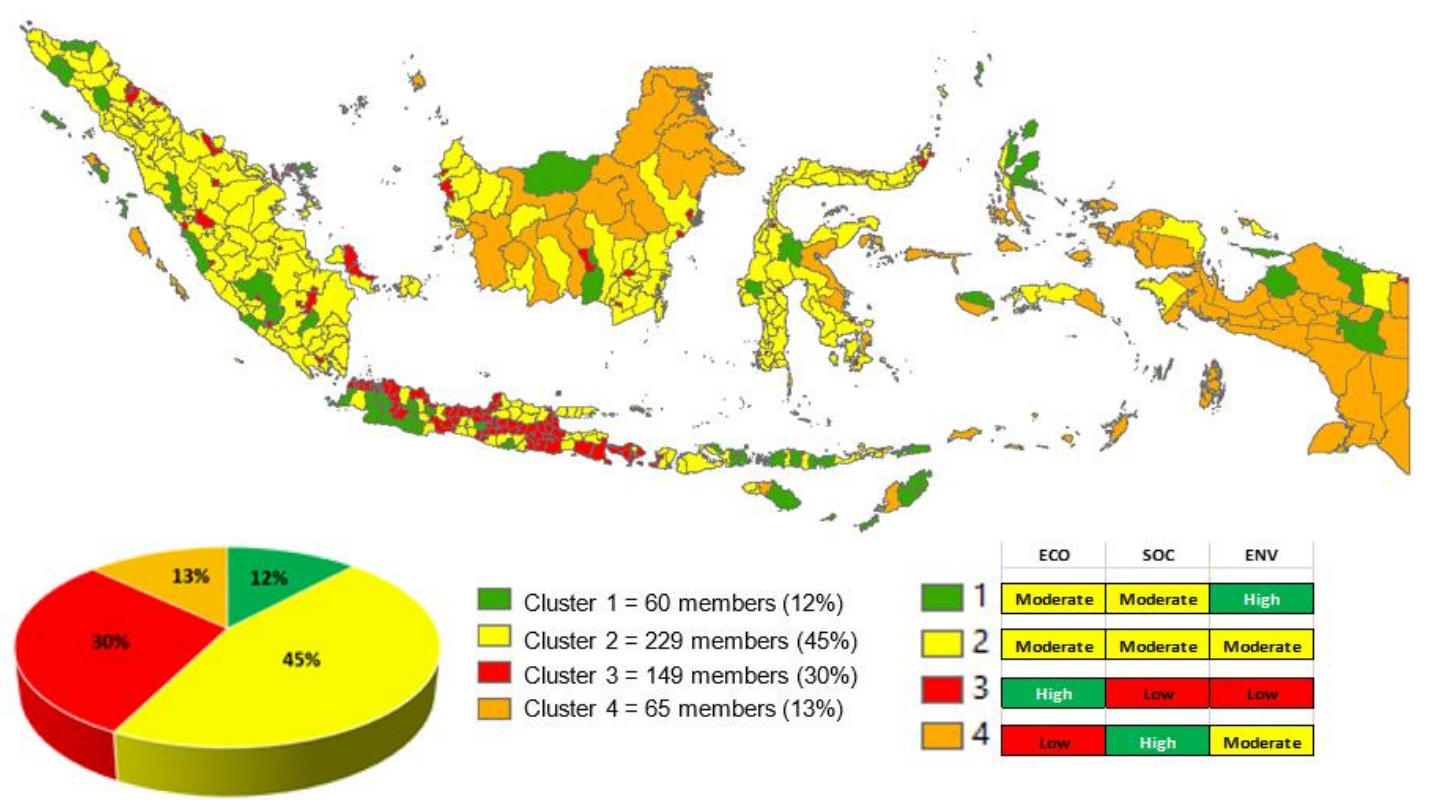

Figure 7. Cluster Map based on $\mathrm{RSI}_{1}$ (Economy), $\mathrm{RSI}_{2}$ (Social), and $\mathrm{RSI}_{3}$ (Environmental) Index Value

\section{Concluding Remarks}

The RSI was developed as a new approach for evaluating and reporting economic, social, and environmental conditions at the regional level to support the integration of three dimensions of sustainability. Based on the spatial distribution map of $\mathrm{RSI}_{1}, \mathrm{RSI}_{2}$, and $\mathrm{RSI}_{3}$, it was found that in general, most of regencies and municipalities in Indonesia have higher regional economic index $\left(\mathrm{RSI}_{1}\right)$ rather than regional social index $\left(\mathrm{RSI}_{2}\right)$ and regional environmental index $\left(\mathrm{RSI}_{3}\right)$. Hence, most of regencies and municipalities have a quite low regional environmental index $\left(\mathrm{RSI}_{3}\right)$ since Indonesia is developing country which most of regencies and municipalities are still pursuing economic growth as shown by the higher value of $\mathrm{RSI}_{1}$. Efforts to pursue economic development are usually conducted by exploiting natural resources, thus impacting on environmental degradation. On the other hand, in some less developed regencies and municipalities have relatively high value of $\mathrm{RSI}_{3}$. Based on that condition, government should pay more attention for environment preservation in order to not only achieve economic growth but also environmental sustainability goal as well.

Developing RSI is a new approach to evaluate regional sustainability degree, in order to increase people's awareness about the importance of sustainable development at the regional level. This approach was able to show the actual condition of regional sustainability performance in all dimensions without making them into one composite index. Based on LISA statistics, regional sustainability performance of the meso-scale spatial units is strongly influenced by the sustainability conditions in its surrounding areas. RSI is a very effective method to indicate the locations of the hotspot issues of sustainable development, it can be used as an effective tool for spatial-based decision-making process. Producing a cluster map of regencies and municipalities by combining the index value of each dimension is very helpful for the decision maker to take action and to determine the appropriate policy for solving the problems in each region.

\section{REFERENCES}

[1] Barbosa GS, Drach PR, Corbella OD. 2014. 'A Conceptual Review of The Terms Sustainable Development and Sustainability'. International Journal of Social Sciences. 3(2): $1-15$

[2] WCED. 1987. 'Report of The World Commission on Environment and Development: Our Common Future'. Oslo.

[3] Nijkamp P and Vreeker R. 2000. 'Sustainability Assessment of Development Scenarios: Methodology and Application to Thailand'. Ecological Economics. 33: 7-27.

[4] Mayer AL. 2008. 'Strength and Weaknesses of Common Sustainability for Multidimensional Systems'. Environment International. 34: 277-291.

[5] Bond R, Curran J, Patrick C, Lee N. 2001. 'Integrated Impact Assessment for Sustainable Development: A Case Study Approach'. World Development. 29(6): 1011-1024.

[6] Spangenberg, J.H. 2002. 'Institutional sustainability indicators: An analysis of the institutions in agenda 21 and a draft set of indicators for monitoring their effectivity'. Sustainable Development 2(10): 103-115.

[7] Dahl AL. 2012. 'Achievements and Gaps in Indicators for Sustainability'. Ecological Indicators. 17: 14-19.

[8] Singh RK, Murty HR, Gupta SK, Dikshit AK. 2009. 'An 
Overview of Sustainability Assessment Methodologies'. Ecological Indicators 9: 189-213.

[9] OECD (Organisation for Economic Co-operation and Development). 2003. 'OECD Environmental Indicators: development, measurement, and use'. Paris, France: Organisation for Economic Co-operation and Development.

[10] Wiek A and Binder C. 2005. 'Solution Spaces for Decision-Making, a Sustainability Assessment Tool for City-Regions'. Environmental Impact Assessment Review. 25: 589-608.

[11] World Bank. 2016. 'Indonesia's Urban Story'. Available online http://www.worldbank.org/en/news/feature/2016/06/14/ind onesia-urban-story (accessed on 17 June 2017)

[12] [11] Tan J, Zhang P, Lo K, Li J, Liu S. 2016. 'The Urban Transition Performance of Resource-Based Cities in Northeast China'. Sustainability 8: 2-17.

[13] Evans A, Strezov V, Evans T. 2015. 'Measuring tools for quantifying sustainable development'. European Journal of Sustainable Development 4(2): 291-300.

[14] Bilbao-Ubillos, J. 2013. 'The limits of Human Development Index: the complementary role of economic and social cohesion, development strategies and sustainability'. Sustainable Development 21: 400-412.

[15] Moran DD, Wackernagel M, Kitzes JA, Goldfinger SH, Boutaud A. 2008. 'Measuring sustainable development nation by nation'. Ecological Economics 64: 470-474.

[16] Nourry M. 2008. 'Measuring sustainable development: some empirical evidence for France from eight alternative indicators'. Ecological Economics 67: 441-456.
[17] Siche JR, Agostinho F, Ortega E, Romeiro A. 2008. 'Sustainability of nations by indices: comparative study between environmental sustainability index, ecological footprint and the emergy performance indices'. Ecological Economics 66: 628-637.

[18] Böhringer C, Jochem PEP 2007. 'Measuring the immeasurable - a survey of sustainability indices'. Ecological Economics 63: 1-8.

[19] [18] Wilson J. Tyedmers P, Pelot R. 2007. 'Contrasting and comparing sustainable development indicator metrics', Ecological Indicators, 7: 299-314.

[20] Strezov V, Evans A, Evans TJ. 2016. 'Assessment of the economic, social, and environmental dimensions of the indicators for sustainable development'. Sustainable Development: 1-12.

[21] Pravitasari, A. E., Saizen, I., Rustiadi, E. 2015. 'Towards Resilience of Jabodetabek Megacity: Developing Local Sustainability Index with Considering Local Spatial Interdependency.

[22] Saefulhakim S. 2008. Permodelan. Modul Analisis Kuantitatif Sosial Ekonomi Wilayah. Program Studi Ilmu Perencanaan Wilayah. Institut Pertanian Bogor. Bogor (in Bahasa Indonesia).

[23] Templ M, Filzmoser P, Reimann C. 2008. 'Cluster Analysis Applied to Regional Geochemical Data: Problems and Possibilities'. Applied Geochemistry (23): 2198-2213.

[24] Finch H. 2005. 'Comparison of Distance Measures in Cluster Analysis with Dichotomus Data'. Journal of Data Science 3: 85-100. 